\title{
The blood resistin level in patients with DM2, depending on the duration of the disease
}

\author{
Alina Urbanovych
}

Department of Endocrinology, Lviv National Medical University, Pekarska 69, 79010, Lviv, Ukraine

\section{ARTICLE INFO \\ Received 27 February 2015 \\ Accepted 24 March 2015}

\section{Keywords:}

resistin,

diabetes mellitus type 2

(DM2),

insulin.

\begin{abstract}
Resistin is still a little known hormone of the adipose tissue. The potential role of resistin in the development of DM2 has been currently investigated. The aim of our study was to detect the resistin blood level in patients with DM2, depending on the duration of the disease. In so doing, a determination of resistin and insulin blood level was conducted in 305 patients with DM2, and in a control group of 32 persons. Before testing, the patients were placed into four groups, depending on the duration of type 2 diabetes. Our results indicate that the resistin level was significantly lower in the control group of patients, in comparison with the DM2 patients groups. Moreover, a significantly lower resistin level was found in group I (firstly diagnosed DM2), in comparison with the groups of patients with a different duration of DM2. No correlation between resistin level and BMI, and between resistin and insulin blood level was found. However, a tendency towards increase of resistin blood level is noticeably evident in co-relation with increment of DM2 duration. In addition, the resistin level was considerably lower in patients with no DM2, when compared with patients with diagnosed DM2. Yet, there was no significant difference in the resistin blood level depending on the sex of the patients at the same duration of DM2.
\end{abstract}

\section{INTRODUCTION}

For a long period of time, adipocyte cells were seen as being relatively inert energy storage areas. However, more recently, it has been revealed that adipose tissue is not only a powerful source of energy, but also a full-fledged endocrine organ, in that adipose tissue synthesizes a large number of cytokines and biologically active substances.

In 2001, a group of researchers from the University of Pennsylvania, conducted a study of the genes which were involved in the process of differentiating adipokines. Their work revealed a previously unknown family of adipokine, which were called 'resistin'. This was found to be a set of hormones of insulin resistance. Research as to their significance and action, however, is still on-going.

The term 'resistin' has been applied to a protein family widely known as 'resistin-like molecules' (RELM). Proteins RELM- $\alpha$ and RELM- $\beta$ also belong to the family. Resistin is a polypeptide that contains 114 amino acid residues, and it is secreted as a dysulphide-combined dimer. It is known to

\footnotetext{
* Corresponding author

e-mail: alinaur@dr.com,

tel. +380682270707
}

be produced in the adipose tissue in mice. Generally, mice demonstrate low weight and little adipose tissue with no resistin - even in a fat-enriched diet. There is an assumption, however, that the level of resistin may be, in mice, a trigger factor of the metabolic disorders associated with diabetes and obesity $[16,13,15]$. It is also known that resistin inhibits insulin-mediated glucose capture by the target tissue. Moreover, it has influence on fat metabolism. In addition, while on the one hand, it is known to be involved in the differentiation of adipocyte cells from pre-adipocytes, on the other hand - it is known to inhibit adipogenesis [10].

Inconsistent results were obtained while studying the role of resistin in humans. Yet, the potential role of the hormone in the development of obesity and DM2 has been investigated. Resistin is primarily released by monocytes/ macrophages in humans. There is a suggestion that level of resistin may be associated with macrophage activation. Furthermore, the results of certain studies support the role of human resistin in the development of insulin resistance and inflammation. Thus, human resistin may be linked with insulin resistance and the development of inflammatory diseases such as DM2 and atherosclerosis [6,12,9,3,1]. 
The aim of our study was to investigate changes of resistin blood level in patients with DM2, depending on the duration of the disease.

\section{MATERIAL AND METHODS}

In our work, 305 patients with DM2 were accepted to the study group, including 154 female and 151 male patients. The control group consisted of 32 healthy persons, including 16 female and 16 male patients. A test of glucose tolerance was conducted for all persons of the control group to reveal overlooked DM2. The diagnosis of DM2 was put forward according to the recommendations of WHO experts. Patients were placed into investigation groups depending on the duration of DM2. Group I: patients with DM2 detected for the first time (untreated DM2); Group II: patients, which had experienced DM2 for a duration of 5 years; Group III: patients with a duration of DM2 for 5-10 years; Group IV: patients with DM2 currency over 10 years.

The patients from the Group I did not accept pharmacological treatment; those in Group II and III were treated by way of administered metformin, sulfanilurea monotherapy or its combination; in Group IV - four patients (11,8\%) received insulin, the others were treated with metformin, sulfanilurea therapy or a combination of this drugs.

The survey was conducted at the Lviv Regional Endocrinological Clinic.

The level of resistin and insulin were compared in groups with different durations of DM2. The groups were comparable by age of the patients and compensation of diabetes, which was assessed by level of HbAlc $(\mathrm{p}>0,05)$.

Written informed consent was obtained from all participants, and the protocol was approved by the local ethics committee (Lviv National Medical University). All precautions regarding the health of the patients and protection of their rights, human dignity, moral and ethical standards were in accordance with the principles of the Helsinki Declaration of Human Rights, the European Convention on Human Rights and Biomedicine, as well as the relevant laws of Ukraine.

Blood sampling was carried out on an empty stomach, after 12 hours of fasting. The level of resistin was determined by the ELISA test, using a set of reagents supplied by "Bio Vendor" (Germany), while blood insulin level was identified through ELISA test, using a set of reagents supplied by "DRG" (Germany). HbA1c level was measured using the cation-exchange high-performance liquid chromatography automatic analyzer "Bio-Rad D-10" (USA). All tests were conducted in the clinical laboratory of Lviv Regional Endocrinological Clinic.

Statistical analysis of the results was performed using the Statistica software package (version 8.0). Assessment of differences between groups with a distribution close to normal was performed using Student's t-test, while correlation analysis was employed to determine the coefficient of Pearson. In the case of non-normal distribution, the Kolmogorov-Smirnov test and correlation analysis to determine the Spearman coefficient were used. The results are presented as the mean value and standard deviation and correlation coefficient $r$. The $p<0.05$ value was considered as reliable.

\section{RESULTS}

The clinical characteristics of the studied groups are presented in Table 1.

Table 1. Clinical characteristics of of studied groups

\begin{tabular}{|c|c|c|c|c|c|c|}
\hline \multirow{2}{*}{ Group } & \multirow{2}{*}{$\begin{array}{l}\text { Duration } \\
\text { of DM2, } \\
\mathrm{N} \text { years }\end{array}$} & \multirow{2}{*}{ Gender } & \multirow{2}{*}{$\mathrm{N}$} & \multicolumn{2}{|c|}{ Age } & \multirow{2}{*}{$\mathrm{BMI}, \mathrm{X} \pm \mathrm{S}$} \\
\hline & & & & $\min -\max$ & $\mathrm{X} \pm \mathrm{S}$ & \\
\hline \multirow{8}{*}{$\begin{array}{l}\text { Type of } \\
\text { DM } 2\end{array}$} & \multirow{2}{*}{$\begin{array}{c}\text { Firstly } \\
\text { diagnosed }\end{array}$} & Male & 57 & $40-65$ & $52,28 \pm 0,90$ & $31,19 \pm 0,73$ \\
\hline & & Female & 55 & $40-64$ & $55,22 \pm 0,78$ & $31,14 \pm 0,72$ \\
\hline & \multirow{2}{*}{$<5$ years } & Male & 53 & $43-65$ & $53,64 \pm 0,76$ & $32,30 \pm 0,72$ \\
\hline & & Female & 60 & $43-64$ & $53,70 \pm 0,73$ & $32,51 \pm 0,79$ \\
\hline & \multirow{2}{*}{$5-10$ years } & Male & 26 & $43-64$ & $53,04 \pm 1,11$ & $28,96 \pm 1,23$ \\
\hline & & Female & 20 & $42-64$ & $53,68 \pm 1,59$ & $33,51 \pm 1,59$ \\
\hline & \multirow{2}{*}{$>10$ years } & Male & 15 & $47-62$ & $53,71 \pm 1,34$ & $28,85 \pm 2,0$ \\
\hline & & Female & 19 & $47-63$ & $56,47 \pm 1,10$ & $32,16 \pm 1,57$ \\
\hline \multirow{2}{*}{ Control } & \multirow{2}{*}{ - } & Male & 16 & $41-59$ & $51,54 \pm 1,87$ & $31,35 \pm 1,80$ \\
\hline & & Female & 16 & $40-58$ & $51,69 \pm 1,28$ & $30,09 \pm 1,40$ \\
\hline
\end{tabular}

Note: $\mathrm{n}$ - number of patients, BMI - body mass index, min-max - minimum and maximum age of patients, $\mathrm{X}$ - arithmetic mean, $\mathrm{S}-$ standard deviation.

All groups were comparable by age and BMI ( $p>0.05)$.

Our results reveal that the level of resistin was significantly lower in the control group, in comparison with Group II $(2,64 \pm 0,20$ v. $3,56 \pm 0,20 \mathrm{ng} / \mathrm{ml}, \mathrm{p}=0.043)$ and when compared with Group III $(2,64 \pm 0,20$ v. 4,16 $\pm 0,47$ $\mathrm{ng} / \mathrm{ml}, \mathrm{p}=0.031)$ and Group IV (2 $64 \pm 0,20$ v. 4,46 $\pm 0,37$ $\mathrm{ng} / \mathrm{ml}, \mathrm{p}=0.004)$.

The insulin and HbAlc level characteristics are presented in Table 2.

Table 2. The insulin and HbA1c content level in DM2 patients with different disease duration

\begin{tabular}{|l|c|c|c|}
\hline \multicolumn{1}{|c|}{ Groups of patients } & $\begin{array}{c}\text { Insulin level } \\
\mu \mathrm{IU} / \mathrm{mL}, \mathrm{X} \pm \mathrm{S}\end{array}$ & $\mathrm{P}$ & $\begin{array}{c}\text { HbA1c } \\
\%, \mathrm{X} \pm \mathrm{S}\end{array}$ \\
\hline $\begin{array}{l}\text { Patients with firstly diagnosed } \\
\text { DM2 }\end{array}$ & $20,47 \pm 0,98$ & & $10,67 \pm 0,35$ \\
\hline $\begin{array}{l}\text { Patients with DM2 duration } \\
\text { of 5 years }\end{array}$ & $21,06 \pm 0,93$ & $\mathrm{P} 2<0,0007$ & $9,13 \pm 0,29$ \\
\hline $\begin{array}{l}\text { Patients with DM2 duration } \\
\text { for 5- 10 years }\end{array}$ & $20,03 \pm 1,72$ & $\mathrm{P} 3<0,03$ & $9,80 \pm 0,32$ \\
\hline $\begin{array}{l}\text { Patients with duration of DM2 } \\
\text { over 10 years }\end{array}$ & $14,40 \pm 1,54$ & $\mathrm{P} 1<0,003$ & $10,30 \pm 0,35$ \\
\hline Control & $17,90 \pm 2,17$ & & \\
\hline
\end{tabular}

Note. $\mathrm{X}$ - arithmetic mean, $\mathrm{S}$ - standard deviation. Probability differences between: P1 - first and fourth groups; P2 - second and fourth groups; $\mathrm{P} 3$ - the $3^{\text {rd }}$ and $4^{\text {th }}$ groups

In this study, the lowest level of insulin was revealed in the DM2 patients in Group IV (patients with a duration of DM2 of over 10 years). Of note, there were no reliable HbA1c level changes in the investigated groups of patients.

Furthermore, the group of patients with newly diagnosed DM2 (Group I) demonstrated lowest resistin level, when compared with the other groups of patients of different duration times of type 2 diabetes $(p<0,005)$. Moreover, we discovered a significant resistin level increase which co-relates in groups with increasing duration of type 2 diabetes $(\mathrm{p}<0,05)$.

Data about resistin level, depending on the duration of type 2 diabetes, is presented in Figure 1. 


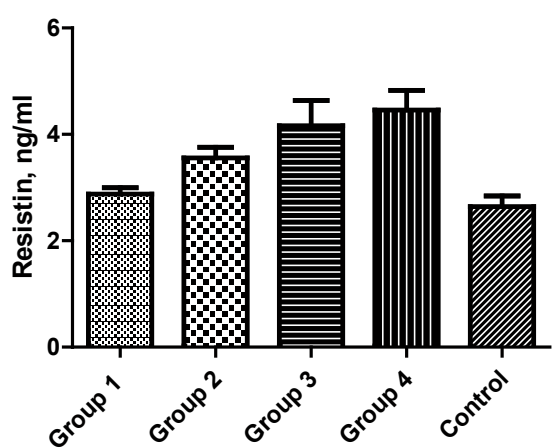

Figure 1. Resistin levels in groups of patients with type 2 diabetes, depending on the duration of disease.

There was no correlation between resistin levels and BMI.

Difference in resistin concentration between female and male patients is presented in Table 3 .

Table 3. The resistin blood level in DM2 female and male patients with different disease duration

\begin{tabular}{|l|c|c|c|}
\hline \multicolumn{1}{|c|}{ Groups of patients } & $\begin{array}{c}\text { Resistun level } \\
\mathrm{ng} / \mathrm{ml}, \text { female } \\
\mathrm{X} \pm \mathrm{S}\end{array}$ & $\begin{array}{c}\text { Resistun level } \\
\mathrm{ng} / \mathrm{ml}, \text { male } \\
\mathrm{X} \pm \mathrm{S}\end{array}$ & $\mathrm{P}$ \\
\hline $\begin{array}{l}\text { Patients with firstly diagnosed } \\
\mathrm{DM} 2\end{array}$ & $2,84 \pm 0,17$ & $2,86 \pm 0,16$ & $\mathrm{P}=0,93$ \\
\hline $\begin{array}{l}\text { Patients with DM2 duration } \\
\text { of 5 years }\end{array}$ & $3,46 \pm 0,28$ & $3,21 \pm 0,23$ & $\mathrm{P}=0,51$ \\
\hline $\begin{array}{l}\text { Patients with DM2 duration } \\
\text { for 5-10 years }\end{array}$ & $5,13 \pm 0,94$ & $3,42 \pm 0,39$ & $\mathrm{P}=0,08$ \\
\hline $\begin{array}{l}\text { Patients with duration of DM2 } \\
\text { over 10 years }\end{array}$ & $4,59 \pm 0,37$ & $3,95 \pm 0,80$ & $\mathrm{P}=0,42$ \\
\hline
\end{tabular}

A significant difference in resistin concentration depending on the sex of the patients with the same duration of DM2 was not discovered.

\section{DISCUSSION}

Current literature suggests that resistin blood level significantly increases within an elongation of DM2 duration. The work of Jinhua Yin et al. also confirms that resistin level, both in blood and in saliva, is higher in patients with firstly diagnosed DM 2, in comparison with a control group with no diabetes [7]. Hasegawa G. at al., in their study, also confirm differences in resistin level in patients with DM2, and in patients without disturbances of glucose metabolism. Moreover, they reveal that the resistin level was significantly higher in patients with DM2, when compared with individuals without DM2. However, no statistically significant difference in resistin level between female and male patients was found [5].Early researchers once considered that the resistin level has influence on fatty acids (FFA) metabolism, and decreases insulin sensitivity to glucose [2], yet, the combination of these factors should cause insulin resistance [11]. Thus, the results of studies regarding this issue still remain controversial. Hence, investigations of insulin resistance development under the influence of hyperresistinaemia is still ongoing. Numerous experimental studies on mice indicate that resistin plays a certain role in glucose metabolism. For example, Rangwala S. at al., conducted a study on mice with chronic hyperresistinaemia. In addition, researchers have shown that resistin has the function of regulating glucose homeostasis, and have established that high chronic level of glucose in the blood leads to fasting hyperglycemia and glucose intolerance [14].

Current research reveals many differences in the results of resistin level studies conducted in animals and humans. Unlike animals, human fat cells produce significantly less amounts of resistin, which only to the degree of $64 \%$ is homologous to mice resistin. This complicates its specification.

Vozarova De Courten B. conducted a study involving overweight DM2 patients. In this, oral glucose tolerance testing was provided for all patients. The results of this study suggest that no correlation exists between resistin and insulin levels and insulin resistance indices. Moreover, a correlation between resistin level and tissue resistance to insulin was not established. However, positive correlation between resistin level and percentage of FAT and between resistin level and level of glucose was confirmed during the second hour of the test [18].

In another set of studies, Tokuyama et al. and Fujinami et al. report that serum resistin level in diabetic patients were significantly higher than in their control group, and this change was negatively correlated with insulin sensitivity $[17,4]$.

Some researchers argue the presence of a positive correlation between resistin and BMI, insulin levels [3]. Yet, Lauders et al. found no correlation between resistin level and DM2 in a survey carried out on 19 patients with DM2 and obesity, and on 17 patients representing the control group [8]. Their results, however, do not match with our results. This may be explained by the different number of surveyed patients.

We saw that resistin blood level increases with increment of DM2 duration. Moreover, the level of insulin (known and reliably confirmed in our study), is reduced with increasing DM2 duration. The assumption can, hence, be made that long-term increasing of resistin blood level results in a reduction of insulin release and can reduce its action due to the increasing of duration of DM2. Probably, sulfanilurea therapy and metformin administration have little effect upon this.

Therefore, according to the results obtained in our study, the conclusion of the necessity of further research can be made. Apart from this, our study may also suggest that elevated resistin blood level can be a trigger factor in the decrease of insulin level and the appearance of subsequent metabolic disorders, regardless of BMI and sex of the DM2 patients.

\section{CONCLUSIONS}

In conclusion, we noticed that:

- resistin level was significantly increased with the increment of DM2 duration;

- individuals without DM2 demonstrate significantly lower resistin blood level, in comparison to patients with DM2; correlation between resistin level and BMI was not observed;

- there was no statistically significant difference in resistin level between female and male DM2 patients with the same duration of disease. 


\section{REFERENCES}

1. Bauer S. et al:: Systemic resistin is increased in type 2 diabetic patients treated with loop diuretics. J. Diabetes Complications, 2011, 25:377-381.

2. Cao H., Hegele R.: Single nucleotide polymorphisms of the resistin (RSTN) gene. J. Hum Genet., 2001; 46: 553-555.

3. Ebtesam A Al-Suhaimi, Adeeb Shehzad.: Leptin, resistin and visfatin: the missing link between endocrine metabolic disorders and immunity. European Journal of Medical Research, 2013, 18:12.

4. Fujinami A. et al.: Enzyme-linked immunosorbent assay for circulating human resistin: resistin concentrations in normal subjects and patients with type 2 diabetes. Clinica Chimica Acta, 2004; 339 (1-2): 57-63.

5. Hasegawa G., et al.: Plasma concentrations of resistin in type 2 diabetic patients. Diabetes, 2003; 52 (1): 82-83.

6. Janke J. et al.: Resistin gene expression in human adipocytes is not related to insulin resistance. Obes. Res., 2002; 10: 1-5.

7. Jinhua Yin et al.: Measurement of Salivary Resistin Level in Patients with Type 2 Diabetes. International Journal of Endocrinology, 2012; 2012: Article ID 359724, 5 p.

8. Lauders $\mathrm{M}$ et al.: Visfatin/PBEF/Nampt and resistin expressions in circulating blood monocytes are differentially related to obesity and type 2 diabetes in humans. Horm Metab Res., 2010 Apr;42(4):268-73

9. Lee J.H. et al.: Circulating resistin levels are not associated with obesity or insulin resistance in humans, and are not regulated by fasting or leptin administration: cross-sectional and interventional studies in normal, insulin-resistant, and diabetic subjects. J. Clin. Endocrinol. Metab., 2003; 88: 4848-4856.
10. McTernan C.L. et al.: Resistin, central obesity, and type 2 diabetes. Lancet, 2002; 36: 46-7.

11. Meier U., Gressner A.M.: Endocrine regulation of energy metabolism: review of pathobiochemical and clinical chemical aspects of leptin, ghrelin, adiponectin and resistin. Clin Chem., 2004; 50: 1511-1525.

12. Nagaev I, Smith U.: Insulin resistance and type 2 diabetes are not related to resistin expression in human fat cells or skeletal muscle. Biochem. Biophys. Res. Commun., 2001; 285: 561-564.

13. Rajala M. et al.: Regulation of resistin expression and circulating levels in obesity, diabetes, and fasting. Diabetes, 2004; 53 (7): 1671-1679.

14. Rangwala S. et al.: Abnormal glucose homeostasis due to chronic hyperresistinemia. Diabetes, 2004; 53: 1937-1941.

15. Shuldier A., Yang R., Gong D.W.: Resistin, obesity and insulin resistance. N Engl J Med., 2001; 345: 1345-1346.

16. Steppan C.M. et al.: The hormone resistin links obesity to diabetes. Nature, 2001; 409: 307-12.

17. Tokuyama Y. et al.: Serum resistin level is associated with insulin sensitivity in Japanese patients with type 2 diabetes mellitus. Metabolism, 2007; 56 (5): 693-698.

18. Vozarova De Courten B. et al.: High serum resistin is associated with an increase in adiposity but not worsening of insulin resistance in Pima Indian. Diabetes, 2004; 53 (9): 1279-1284. 